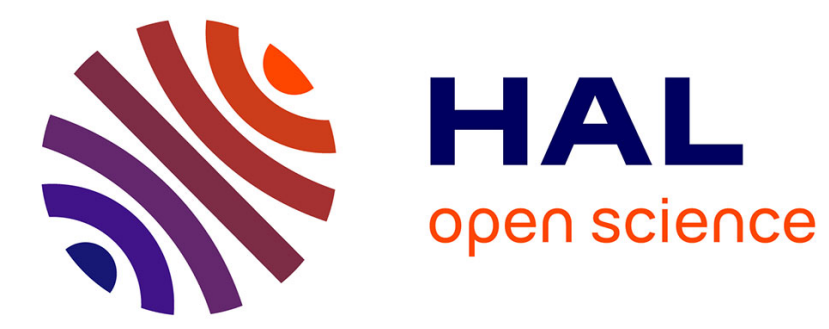

\title{
DISSOCIATION OF MOLECULAR IODINE DURING MIXING WITH SINGLET OXYGEN FLOW
}

\author{
A. Dvoryankin, N. Kudryavtcev, Yu. Kulagin
}

\section{To cite this version:}

A. Dvoryankin, N. Kudryavtcev, Yu. Kulagin. DISSOCIATION OF MOLECULAR IODINE DURING MIXING WITH SINGLET OXYGEN FLOW. Journal de Physique IV Proceedings, 1991, 01 (C7), pp.C7-655-C7-658. 10.1051/jp4:19917175 . jpa-00250853

\section{HAL Id: jpa-00250853 https://hal.science/jpa-00250853}

Submitted on 1 Jan 1991

HAL is a multi-disciplinary open access archive for the deposit and dissemination of scientific research documents, whether they are published or not. The documents may come from teaching and research institutions in France or abroad, or from public or private research centers.
L'archive ouverte pluridisciplinaire HAL, est destinée au dépôt et à la diffusion de documents scientifiques de niveau recherche, publiés ou non, émanant des établissements d'enseignement et de recherche français ou étrangers, des laboratoires publics ou privés. 


\title{
DISSOCIATION OF MOLECULAR IODINE DURING MIXING WITH SINGLET OXYGEN FLOW
}

\author{
A.N. DVORYANKIN, N.Yu. KUDRYAVTCEV and Yu.A. KULAGIN \\ Department of Optics, P.N. Lebedev Physical Institute, Leninsky Prospekt 53, Moscow 117924, \\ USSR
}

\begin{abstract}
The analytical model of the molecular iodine dissociation in the singlet oxygen(SO) media is considered. The mean number of SO molecules, which are spent to dissociate one iodine molecule, is evaluated, depending on the initial iodine, singlet and ground state oxygen, and water vapor concentrations. The two-dimensional numerical modeling of mixing of SO and iodine containing flows was done to investigate the influence of mixing on the process of the iodine dissociation and gain distribution.
\end{abstract}

\section{ANALYTTCAL CONSIDERATION.}

The main processes which determine the gain in the active media of the Chemical Oxygen Iodine Laser (COIL) are known [1] today (see Tab.1,2). It allows to make numerical analysis in order to improve the operational characteristics of COIL. The exception is the mechanism of the molecular iodine dissociation including the role of electronically-xxited states $I_{2}\left(A, A^{2}, B\right)$ and the number of $S O$ molecules, which are spent to dissociate one iodine molecule.

The rate constants of the processes, which govern the population and depopulation of the electronically excited states $I_{2}\left(A, A^{\prime}\right)$ are poorly known, so it is difficult to estimate their role during dissociation.

The first rate-limiting step of the dissociation is the population in collisions with $\mathrm{O}_{2}(\mathrm{a})$ or $\mathrm{I}^{*}$ of highly-excited vibrational levels of the ground state iodine molecule $\mathrm{I}_{2}{ }^{+}(\mathrm{X}, 20<\mathrm{v}<40)$ Then $\mathrm{I}_{2}{ }^{+}$can dissociate in the second collision with them. The population of electronically excited states $I_{2}\left(A, A^{\prime}\right)$ in collisions of vibrationally thermalised $I_{2}(X)$ molecules with $\mathrm{O}_{2}(\mathrm{a})$, $\mathrm{I}^{*}$ is impossible, because their energies $E \mathrm{~A}^{\prime}=9989 \mathrm{~cm}^{-1}$ $E A=10846 \mathrm{~cm}^{-1}$ are sufficiently higher than energies of $\mathrm{O}_{2}(\mathrm{a})$ and $\mathrm{I}^{*}$ which are 7882 and $7603 \mathrm{~cm}^{-1}$ respectively. The iodine dissociation can also occur in collisions of $\mathrm{I}_{2}(\mathrm{X})$ with $\mathrm{O}_{2}(\mathrm{~b})$, but the sequential mechanism is more effective in the COIL active medium. The excited iodine atom $\mathrm{I}^{*}$ is much more effective than $\mathrm{O}_{2}(\mathrm{a})$ for the ground state $I_{2}(X, v)$ excitation, so the rate of dissociation increases during the molecular iodine dissociation, and the dissociation has a chain-like character. In [2] the sequential model of $\mathrm{I}_{2}$ dissociation in SO medium with one intermediate excited state of $I_{2}$ molecule was suggested.which can satisfactory explain experimental results $[2,3]$. For premixed case assuming steady -state conditions for all excited species and neglecting $\mathrm{O}_{2}(\mathrm{a})$ concentration change during $I_{2}$ dissociation in [2] it was obtained an equation for the temporal behavior of $I_{2}$ concentration and its analytical solution. This equation and its solution can be written in the forn

$$
\mathrm{d} / \mathrm{dt}\left[\mathrm{I}_{2}\right]=-\mathrm{k}_{\mathrm{c}}\left[\mathrm{I}_{2}\right]\left\{(1+\delta)\left[\mathrm{I}_{2}\right]_{0}-\left[\mathrm{I}_{2}\right]\right\} \quad(1) ; \quad\left[\mathrm{I}_{2}(\mathrm{t})\right]=\left[\mathrm{I}_{2}\right]_{0}(1+\delta) /(1+\delta \exp (\mathrm{t} / \tau))
$$

where $\mathrm{k}_{\mathrm{c}}=\alpha\left(\partial \mathrm{k}_{3}+\eta \mathrm{k}_{9}\right)$-effective value of the rate constant for the chain dissociation $\delta=\left(v k_{2}+\eta k_{8}\right)\left[\mathrm{O}_{2}(\mathrm{a})\right] / \mathrm{k}_{\mathrm{c}}\left[\mathrm{I}_{2}\right]_{0}$ - the ratio of dissociation rates for $\mathrm{O}_{2}(\mathrm{~b})$ and sequential dissociation which is typically of order $10^{-2}, \eta=\mathrm{k}_{10}\left[\mathrm{O}_{2}(\mathrm{a})\right] /\left(2 \mathrm{k}_{12} \mathrm{i}\left[\mathrm{Q}_{\mathrm{i}}\right]+\mathrm{k}_{10}\left[\mathrm{O}_{2}(\mathrm{a})\right]\right)$ and $\vartheta=\mathrm{k}_{7}\left[\mathrm{O}_{2}(\mathrm{a})\right] / 2 \mathrm{k}_{4} \mathrm{i}\left[\mathrm{Q}_{\mathrm{i}}\right]$ are related to the efficiency of the sequential and $\mathrm{O}_{2}(\mathrm{~b})$ dissociation $a=2 \mathrm{k}_{1}\left[\mathrm{O}_{2}(\mathrm{a})\right] /\left(\mathrm{k}_{1}\left[\mathrm{O}_{2}(\mathrm{a})\right]+\mathrm{k}_{-1}\left[\mathrm{O}_{2}(\mathrm{x})\right]\right)$ - the mean number of the excited iodine atoms which appear after one iodine molecule dissociation $\tau=\left\{(1+\delta) \mathrm{K}_{\mathrm{c}}\left[\mathrm{I}_{2}\right]_{0}\right\}^{-1}$ -characteristic time of $I_{2}$ dissociation

The time it takes the iodine concentration to decrease $\mathrm{N}$ times as a result of dissociation equals $t_{d s}=\tau[\ln (1+1 / \delta-1 / N \delta)+\ln N]$. One can distinquish two stages of dissociation. During the initiation period $t_{i}=\tau \ln 1 / \delta$ the initial iodine concentration $\left[I_{2}\right]_{0}$ decreases approximately twice, then during the period $t_{n}=\tau \operatorname{lnN}$ it becomes $\left[\mathrm{I}_{2}\right]_{0} / \mathrm{N}$. 
As the result of the fast energy exchange reaction (1) the $I^{*}$ atoms and SO molecules form a united pool of electronically-excited particles. The rate of its relaxation depends significantly on the current $\mathrm{I}^{*}$ atoms concentration and consequently on the current $I_{2}(X)$ concentration. So using Heidner's approximations [2] one can obtain the equation for $\mathrm{O}_{2}(\mathrm{a})$ relaxation during $\mathrm{I}_{2}$ dissociation

$$
\mathrm{d} / \mathrm{dt}\left[\mathrm{O}_{2}(\mathrm{a})\right]=\mathrm{P}\left[\mathrm{I}_{2}\right]^{2}-\mathrm{M}\left[\mathrm{I}_{2}\right]-\mathrm{L}
$$

The r.h.s. of (2) as that of (1) has a quadratic dependence on the current $I_{2}$ concentration. $P, M, L-$ are. complicated expressions, depending on $\mathrm{O}_{2}(a, \mathrm{X})$ and quenchers concentrations.

Assurning that relative change of $\mathrm{O}_{2}$ (a) concentration is small, one can solve equations (1) and (2) together to obtain the analytical solution for the $\mathrm{O}_{2}(\mathrm{a})$ concentration change during $\mathrm{I}_{2}$ dissociation. During the $\mathrm{I}_{2}$ dissociation the decrease of $\mathrm{O}_{2}(\mathrm{a})$ concentration equals

$$
\left[\mathrm{O}_{2}(\mathrm{a})\right]_{0}-\left[\mathrm{O}_{2}(\mathrm{a})\right]=(\alpha+\mathrm{n})\left[\mathrm{I}_{2}\right]_{0}(1-1 / \mathrm{N})+\mathrm{W}_{\mathrm{i}} \mathrm{t}_{\mathrm{i}}+\mathrm{W}_{\mathrm{q}} \mathrm{t}_{\mathrm{n}}
$$

The last two terms account for quenching of excited particles during dissociation and $W_{q} \gg W_{i}$, where

$W_{\mathrm{q}}=\left\{\sum_{\mathrm{k}_{5}} \mathrm{i}\left[\mathrm{Q}_{\mathrm{i}}\right]+\mathrm{k}_{2}\left[\mathrm{O}_{2}(\mathrm{a})\right]\right\}\left[\mathrm{O}_{2}(\mathrm{a})\right]+\alpha\left\{\mathrm{k}_{6} \mathrm{i}\left[\mathrm{Q}_{\mathrm{i}}\right]+\mathrm{k}_{3}\left[\mathrm{O}_{2}(\mathrm{a})\right]\right\}\left[\mathrm{I}_{2}\right]_{0}$

$\mathrm{W}_{\mathrm{i}}=\left\{\mathrm{q}_{\mathrm{a}}+\mathrm{k}_{2}\left[\mathrm{O}_{2}(\mathrm{a})\right]+(1+\delta) \mathrm{k}_{8}\left[\mathrm{I}_{2}\right] \mathrm{o}\right\}\left[\mathrm{O}_{2}(\mathrm{a})\right\}-\alpha \delta\left\{2 \mathrm{k}_{6} \mathrm{i}\left[\mathrm{Q}_{\mathrm{i}}\right]+\mathrm{k}_{3}\left[\mathrm{O}_{2}(\mathrm{a})\right]+(1+\delta) \mathrm{kg}_{\mathrm{g}}\left[\mathrm{I}_{2}\right]_{0}\right\}\left[\mathrm{I}_{2}\right]_{0}$

are the quenching rates on the chain and initial stages of dissociation. The main quenching process is the excited iodine atom quenching on the chain stage of dissociation so one can obtain the following expression for the mean number of $\mathrm{SO}$ molecules, spent to dissociate one iodine molecule.

$$
\Delta=\left\{\left[\mathrm{O}_{2}(\mathrm{a})\right]_{0}-\left[\mathrm{O}_{2}(\mathrm{a})\right]\right) /\left[\mathrm{I}_{2}\right]_{0}=\alpha+\mathrm{n}+\mathrm{q}
$$

where $\alpha$ SO molecules are spent to excite iodine atoms, $n$ molecules, $n=1+\mathrm{kg}_{9} /\left(\boldsymbol{v}_{\mathrm{k}}+\eta \mathrm{qk} g\right) \simeq 1+1 / \eta$, are spent for $\mathrm{I}_{2}$ dissociation $q=\alpha \mathrm{t}_{\mathrm{n}}\left\{\Sigma_{\mathrm{k}_{6}}{ }\left\{\mathrm{Q}_{\mathrm{i}}\right]+\mathrm{k}_{3}\left[\mathrm{O}_{2}(\mathrm{a})\right]\right\}$ - the number of excited particles which are quenched during dissociation. Since $t_{n}$ inversely proportional to the initial iodine concentration the quenching term in (3) has the same dependence $q \sim\left[\mathrm{I}_{2}\right]_{0}{ }^{-1}$. Water vapor is a significant quencher of the excited particles in the active medium of COIL. The dependence of $\Delta$ on relative water vapor concentration $h=\left[\mathrm{H}_{2} \mathrm{O}\right] /\left\{\left[\mathrm{O}_{2}(\mathrm{a})\right]+\left[\mathrm{O}_{2}(\mathrm{x})\right]\right\}$ is plotted on fig.1 for different $I=\left[I_{2}\right]_{0} /\left\{\left[\mathrm{O}_{2}(\mathrm{a})+\left\{\mathrm{O}_{2}(\mathrm{X})\right]\right\}\right.$-initial iodine concentrations for typical COIL conditions: $\left(\left[\mathrm{O}_{2}(\mathrm{a}) / \mathrm{O}_{2}(\mathrm{X})\right]=1, \mathrm{~h}<0,05 \mathrm{I}<0,01\right)$. Dots are results of our and [4] modelling, cross - experimental results [4]. They are in satisfactory agreement with the results of our analytical prediction.

\section{INFLUENCE OF MIXING WITH SINGLET OXYGEN ON THE $I_{2}$ DISSOCIATION.}

From the analytical consideration it follows that the characteristic time of the iodine dissociation is inversely proportional to the initial iodine concentration. This can lead to sufficient difference in the experimental results and one-dimensional modelling predictions when a prexnixed flow approximation is used. Typically the averaged over the cross section of the COIL channel iodine concentration is $(5-10) \cdot 10^{14} \mathrm{~cm}^{-3}$ and calculated for the premixed case dissociation time is of order $t_{d s}=(2-5) 10^{-4} \mathrm{~s}$. In real devices in the region of the iodine injection its concentration can be an order of magnitude higher. This leads to sufficiently faster dissociation if dissociation time is smaller than the diffusion one and changes the place of the maximum gain respectively to the premixed case. In the typical COIL conditions the iodine molecular diffision coefficient is $D=(1-2) 10^{2}$ $\mathrm{cm}^{2} \mathrm{~s}^{-1}[4]$ and the characteristic diffusion time $\mathrm{t}_{\mathrm{df}}=\mathrm{L}^{2} / \mathrm{D}=(1-5) 10^{-3} \mathrm{~s}$ where $\mathrm{L}=0.5-1 \mathrm{~cm}$ is a typical distance between the holes through which iodine is injected. Since $t_{d f}$ is sufficiently greater than $t_{d s}$ the iodine dissociation will proceed in highly inhomogeneous conditions and the gain will strongly vary across the SO flow depending on the distance from the place of the iodine injection [6].

Here we report the results of numerical modeling which was done in order to investigate the influence of mixing on the iodine dissociation and gain distribution in the COI medium. The stationary two-dimensional parabolic approxination of gas dynamic was used [7]. The kinetic scheme accounted for all the processes 1-12 (see tab.1,2).

The gain was calculated on the $I\left({ }^{2} \mathrm{P}_{1} / 2, \mathrm{~F}=3 \rightarrow 2 \mathrm{P}_{3} / 2, \mathrm{~F}=4\right)$ transition assuming equilibrium population of superfine structure components and Doppler line width. 
The geometry of mixing and initial parameters of the mixing flows were chosen to approximate the conditions of experimental device [8] because overall diagnostics in this device is planned [9] including the iodine distribution in the flow. In this device the iodine is injected at a $45^{\circ}$ angle to the flow direction through the holes in the tubes placed at a distance of $19 \mathrm{~mm}$ from each other. In our modeling the gas flow is calculated between two symmetry axes placed at a distance $L=9,5 \mathrm{~mm}$ ( see fig.2). The SO flow $F_{1}$ containes $\mathrm{O}_{2}(\mathrm{a}): \mathrm{O}_{2}(\mathrm{X}): \mathrm{O}_{2}(\mathrm{~b}): \mathrm{H}_{2} \mathrm{O}: \mathrm{Cl}_{2}=0,6: 0,4: 3 \cdot 10^{-5}: 0,03: 0,04$ torr, has a temperature $\mathrm{T}_{1}=233 \mathrm{~K}^{0}$ and velocity $\mathrm{u}_{1}=55$ $\mathrm{m} / \mathrm{s}$. Flow $\mathrm{F}_{2}$ contains $\mathrm{I}_{2}: A r=0,19: 0,88$ torr , has temperature $T_{2}=330 \mathrm{~K}^{0}$ and velocity $\mathrm{u}_{2}=1,42 \cdot \mathrm{u}_{1}$. It is injected through the hole $h=0,5 \mathrm{~mm}$ at a $45^{\circ}$ angle to the main flow. The ratio of the averaged over the channel cross section iodine concentration to the total oxygen one $I=\left[I_{2}\right]_{a v} /\left\{\left[O_{2}(a)\right]+\left[O_{2}(X)\right]\right\}=0,007$. The results of calculations are shown on fig.2-4. Fig.2 shows the isolines of total iodine concentration $I_{t}=2 \cdot\left[I_{2}\right]+\left[I^{*}\right]+[I]$. One can see that mixing occurs at the distance of order $I_{m}=7 \mathrm{~cm}$ after injection. Fig. 3 shows the gain distribution in several cross sections. It is highly inhomogeneous in the region of maximal gain and becomes near uniform only at the distance $\sim_{m}$. On fig.4 the averaged over the channel cross section results of the above mentioned calculations are compared with the results for the premixed case with equal averaged parameters. Full lines show the distribution of averaged gain along the flow for the inhomogeneous (1) and premixed (2) cases. Broken lines show the ratio of the averaged undissociated molecular iodine concentration to the initial one for inhomogeneous (1) and premixed (2) cases. One can see that in the inhomogeneous case the dissociation proceeds in the region of high local iodine concentration noticeably faster than in the premixed case which leads to marked difference in the position of maximal averaged gain and inhomogeneous gain distribution across the COIL channel. So the mixing effects play significant role in the COIL active medium and should be accounted for in realistic COIl modelling.

Table.1 The kinetic scherne of COLL active medium.

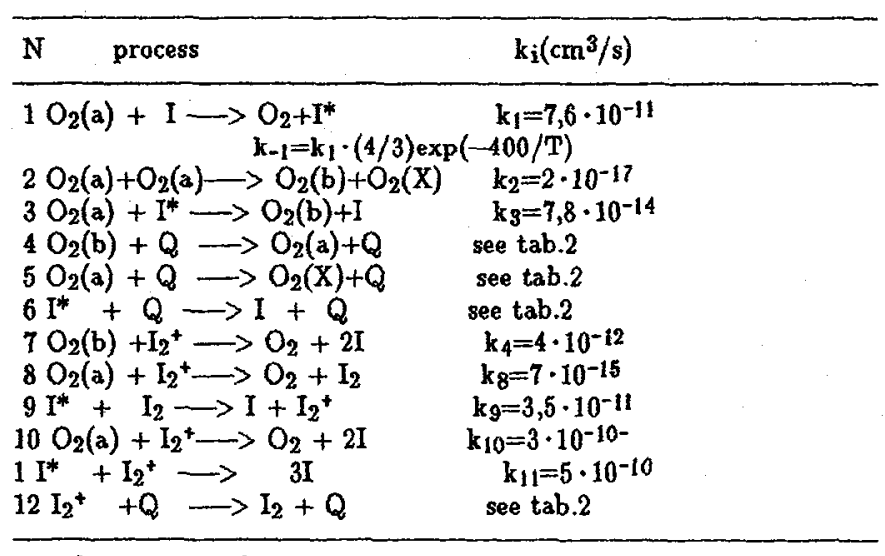

$I=I\left({ }^{2} P_{3} / 2\right), I^{*}=I\left({ }^{2} P_{1} / 2\right), I_{2}{ }^{*}=I_{2}(X, 20<v<40)$.

Table.2 Quenching rate constants

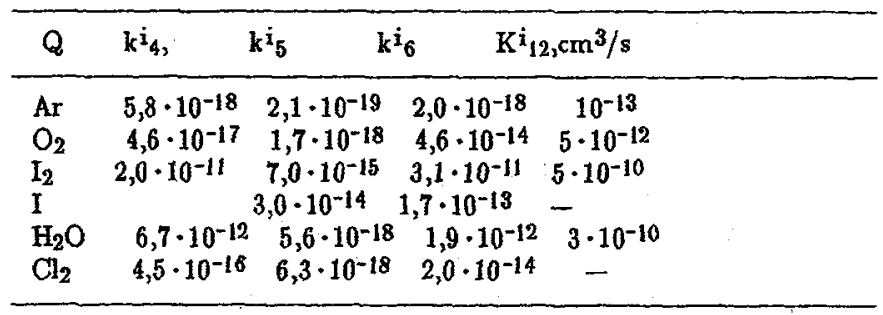



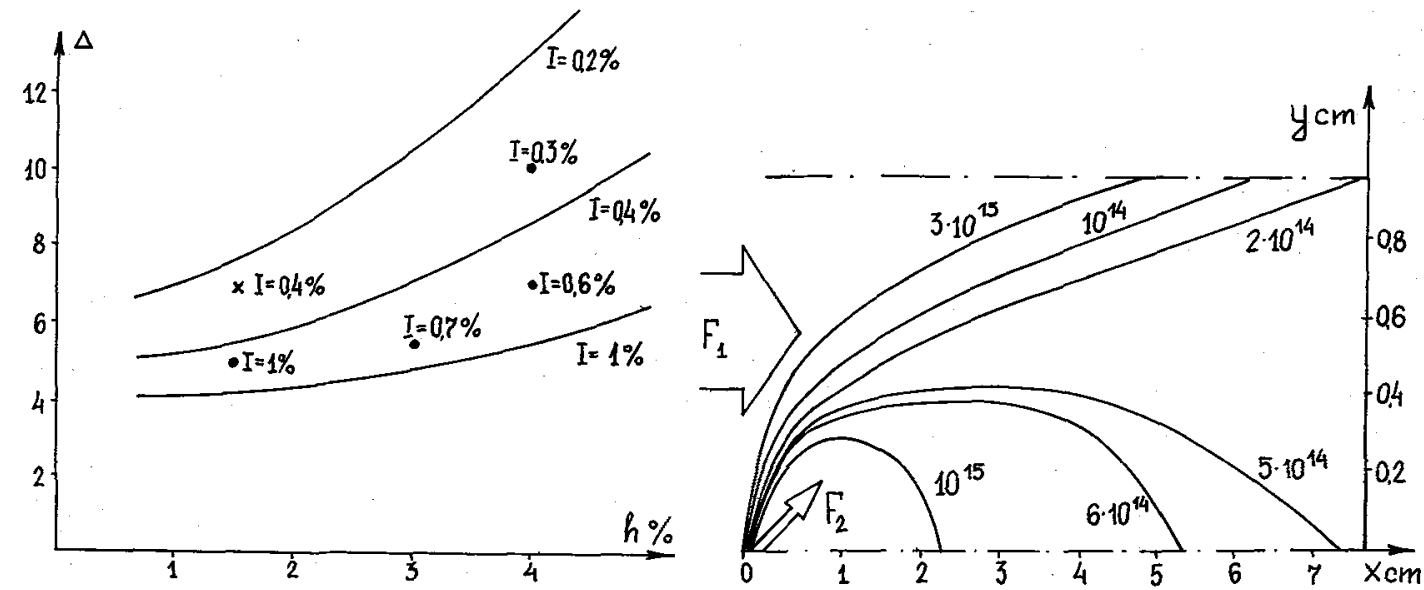

Fig.1 $\Delta$ versus $h$ for different I

Fig.2 The iodine concentration distribution

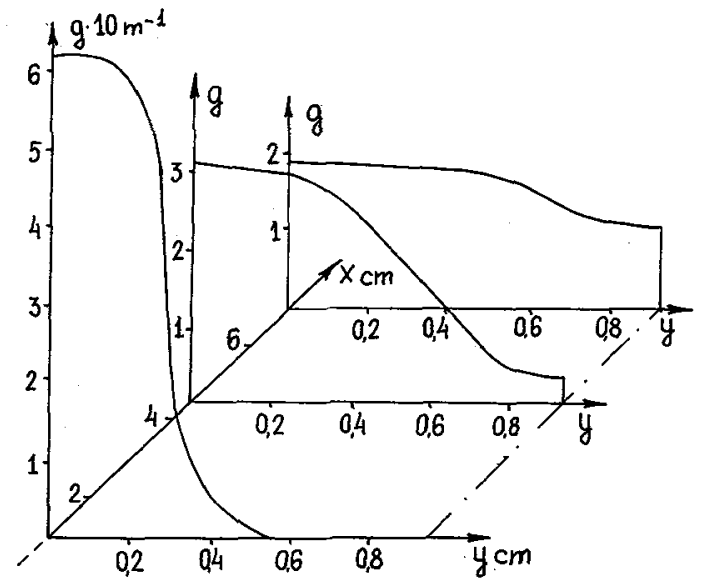

Fig.3 Distribution of the gain. across the flow

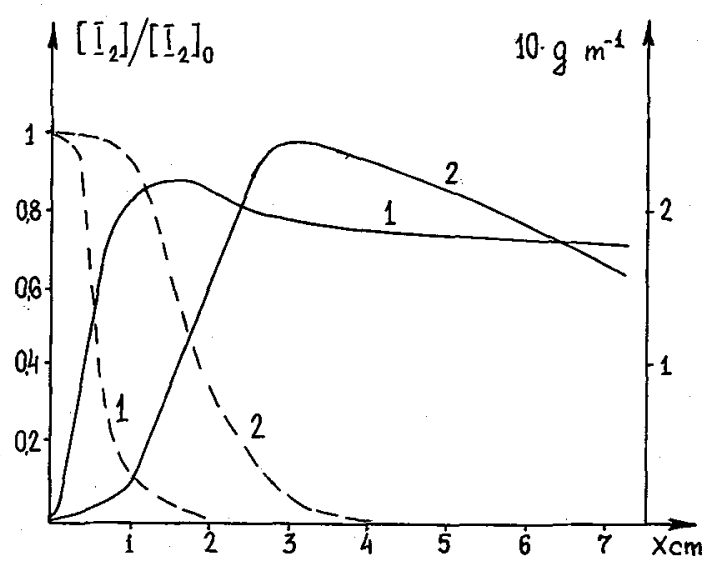

Fig.4 Distribution of the gain and $\mathrm{I}_{2}$ along the flow

\section{References}

1.Didukov A.I.,Kulagin Yu.A.,Shelepin L.A. etcet. Kvant.Elektron.(Sov),16(1989)892

2.Heidner R.F.,Gardner C.E.,Segal G.I. etcet.J.Phys.Chem.,87,(1983)2348

3.Watanabe K.,Kashiwabara S.,Fujimoto R. J.Appl.Phys.59(1986)43

4.Bacis R., Churassy S. Gas flow and chemical lasers. ed. Rosenwacs S. Springer (1987)142.

5.Fisk G.A.,Hays G.N., J.Chern.Phys 77(1982)4965

6.Dvoryankin A.N.,Kulagin Yu.A.,Kudryartcev N.Yu. 8th GCL,Madrid,1990,SPIE Proc. v.1397,p.247

7.Spaulding D.B. "Genmix - a general computer program for two-dimension parabolic

...phenomena".,Oxford,.Pergamon Press 1977

8.Barnault B.,Barraund R.,Forestier L. etset.8th GCL,Madrid,1990,SPIE Proc. v.1397

9,Georges E.,Barraud R.,Mouthon A. 8th GCL,Madrid,1990,SPIE Proc. v.1397 